\title{
Analysis of a Water Distribution Network by Newton-Raphson Multivariable Method: A Case of Negligible Minor Losses
}

\author{
Erigi Ifiemi John Sodiki Barinyima Nkoi \\ Department of Mechanical Engineering, Rivers State University \\ P. M. B. 5080, Port Harcourt, Nigeria
}

\begin{abstract}
A logical, analytical evaluation of a water supply network is a daunting engineer's task. Amongst other concerns, concentrated effort is directed at forestalling huge, avoidable installation and operation costs. This paper examines the water supply network for a two-wing student hostel, consisting of 20 rooms per block and 10 blocks per hostel wing. The plumbing fixtures per block were noted as 6 shower faucets, 8 lavatory sinks, 6 water closets and 2 hose bibs. A water supply pipe network consisting of 13 pipe sections was proffered. Solution sets of the network were generated through a computer implementation of a Newton-Raphson multivariate procedure and a pipe-sizing algorithm. Each solution set is a data collection of a possible mix of 13 pipe sizes and their respective flow rates that satisfy the fluid dynamics conditions and the acceptable velocity range of $0.5 \mathrm{~m} / \mathrm{s}$ to $2.44 \mathrm{~m} / \mathrm{s}$. An optimal solution set is further selected as one with the least head loss at the first index node. This work is a viable tool for analyses of networks with similar scope.
\end{abstract}

Keywords: Head Loss Optimization, Pipe Network Analysis, Newton-Raphson Method, Velocity Constraints.

DOI: $10.7176 /$ ISDE/11-2-03

Publication date:March $31^{\text {st }} 2020$

\section{Introduction}

The provision of water at the reach of her citizens has been one of the principal civic responsibilities of government. In all instances where this responsibility is tackled, water is drawn up from a natural source, treated and made suitable for consumption and channeled through a large web of pipes, to several accessible discharge points. Institutions, such as hospitals and schools, also ensure the availability and accessibility of water at strategic locations in wards and hostels, respectively. While not the same in complexity, a miniature scale of a municipalsized water transport network is utilized in these cases.

According to Swamee and Sharma (2008), the water transport systems essentially consist of 4 main components; namely water source and intake works, storage and treatment works, transmission mains and distribution mains. Such a distribution network may have different configurations depending upon the layout of the area. Looped configurations are preferred over branched configurations on occasions of the high-reliability requirement of water services. Abdulhamid (2016) affirmed that $80 \%$ to $85 \%$ of the cost of a water supply project is expended in the transmission and distribution sections of the system.

For the purpose of substantial cost reduction and meeting project needs, the conception, design and installation demand a much systematic, rational approach. The earliest systematic looped network solution model was introduced by Cross (1936). Thereafter, Epp and Fowler (1970) demonstrated another method of analysis, by first adopting the Newton-Raphson method as a more efficient technique. A completely different, but equally competitive method, now known as Linear Theory, was formulated by Wood and Charles (1972). Nevertheless, the Newton-Raphson method has been hailed for its "Superior Convergence" characteristics (Nielsen, 1990). Although Toldini and Pilati (1988) introduced yet another method, known as the Global Gradient method, it is a modification of the Newton-Raphson method. These formulated methods of network solution are usually facilitated by the computer.

The present work utilizes the Darcy-Weisbach approach, together with Colebrook-White and HagenPoiseuille equations, and deals with the difficulties brought about by their combinations using the NewtonRaphson method. The flow velocity constraints, suggested by Kocyigit et al (2015), imposed by Uniform Plumbing Code (2016), is used to streamline the network solution set. The velocity constraint imposition was also studied by Suribabu (2012), but his work varied from previous works; firstly, in its preference of Darcy-Weisbach equation to the Hazen-William; secondly, in its choice of head loss/tank elevation minimization objectives as against pipe cost minimization, in the selection of an optimal network solution; and thirdly, in its pipe-selection algorithm.

\section{Materials and Methods}

2.1: Materials

The field measurements of distances, plumbing fixture types in use and their quantities were collected. A configuration of pipe network was then proffered. A pipe manufacturer's catalogue of rigid (unplasticized) Schedule-40 Polyvinyl Chloride (PVC) diameter specifications, pipe roughness, and the velocity and residual pressure requirements of Uniform Plumbing Code (2016) were used for this study. This pipe type was chosen due 
to its ready availability, low installation and maintenance cost, suitability for conveyance of cold water aground and underground, and other favourable attributes. From these data, fluid dynamics equations, mathematical methods and a pipe-sizing algorithm were employed to obtain other relevant network parameters for the assessment of the network.

\section{2: Methods}

The analysis and assessment of the network were done with the use of relevant fluid dynamics concepts, principles, models and equations, which were further treated by suitable mathematical methods.

2.2.1: Layout and Description of Proffered Distribution Network

The proffered distribution network is shown schematically in Fig. 1.

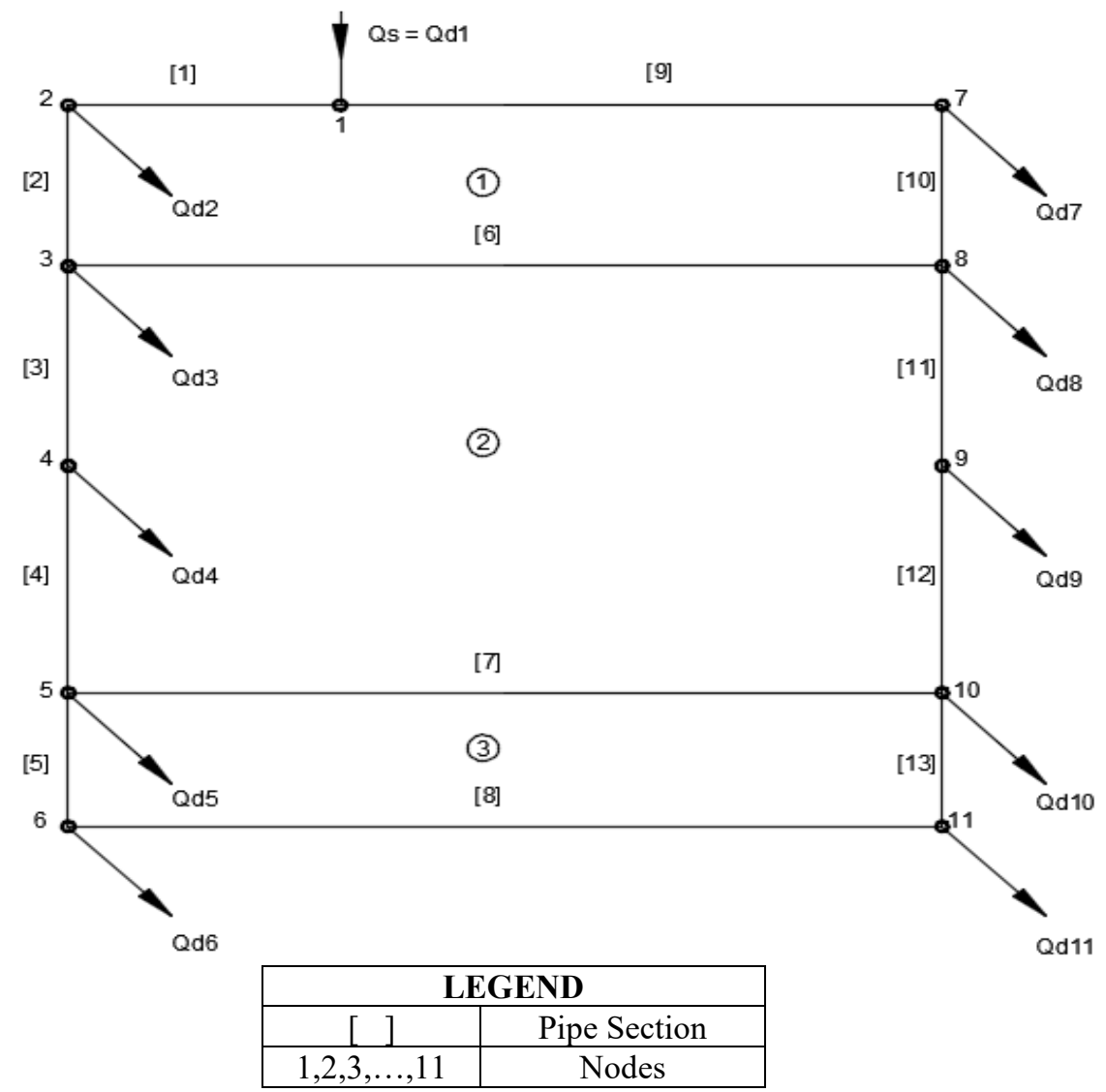

Fig. 1. Schematic diagram of the proposed water distribution network

The proposed network follows from the architectural layouts of the hostels. On-field measurements were taken and the pipe lengths connecting discharge/delivery points were estimated. Each discharging node supplies a block's toilets and bathrooms. The nodes numbered 2 to 6 are delivery points to one wing of the hostel and those numbered 7 to 11 are delivery points to the other wings. The pipes are designated by the nodes of their ends. The pipe lengths (inter-nodal distances) are presented in Table 1. 
Table 1: Pipes and their lengths

\begin{tabular}{|c|c|c|}
\hline $\begin{array}{c}\text { Pipes } \\
\text { (designated number) }\end{array}$ & $\begin{array}{c}\text { Pipes (node-node } \\
\text { identification) }\end{array}$ & $\begin{array}{c}\text { Lengths } \\
(\mathrm{mm})\end{array}$ \\
\hline 1 & $1-2$ & 37475 \\
\hline 2 & $2-3$ & 31918 \\
\hline 3 & $3-4$ & 31918 \\
\hline 4 & $4-5$ & 31918 \\
\hline 5 & $5-6$ & 31918 \\
\hline 6 & $3-8$ & 85950 \\
\hline 7 & $5-10$ & 85950 \\
\hline 8 & $6-11$ & 85950 \\
\hline 9 & $1-9$ & 48475 \\
\hline 10 & $7-8$ & 31918 \\
\hline 11 & $8-9$ & 31918 \\
\hline 12 & $9-10$ & 31918 \\
\hline 13 & $10-11$ & 31918 \\
\hline
\end{tabular}

In Fig. 1, the $Q_{d} S$ at the nodes designate the discharge deliveries at the respective nodes where water is accessed for consumption; and water supply into the distribution network is done at node ' 1 ', which shall hereafter sometimes be referred to as the source node.

2.2.2: Pipe Size Catalogue

The schedule 40 PVC pipe is manufactured in various sizes. A catalogue of the sizes of (sch.40) PVC pipes manufactured for practical plumbing is given by Table 2 .

Table 2: Standard schedule 40 PVC pipe dimensions (Harrison, 2018).

\begin{tabular}{|c|c|c|c|}
\hline \multirow[t]{2}{*}{ S/No } & \multirow[t]{2}{*}{$\begin{array}{l}\text { Nominal Pipe Size } \\
\text { (inch) }\end{array}$} & \multicolumn{2}{|c|}{$\begin{array}{c}\text { Average Internal } \\
\text { Diameter }\end{array}$} \\
\hline & & (inch) & $(\mathrm{mm})$ \\
\hline 1 & $1 / 4$ & 0.249 & 6.32 \\
\hline 2 & $1 / 4$ & 0.344 & 8.74 \\
\hline 3 & $1 / 2$ & 0.473 & 12.04 \\
\hline 4 & $1 / 2$ & 0.602 & 15.29 \\
\hline 5 & $3 / 4$ & 0.804 & 20.42 \\
\hline 6 & 1 & 1.029 & 26.14 \\
\hline 7 & $1 \frac{1}{4}$ & 1.360 & 34.54 \\
\hline 8 & $11 / 2$ & 1.590 & 40.39 \\
\hline 9 & 2 & 2.047 & 51.99 \\
\hline 10 & $21 / 2$ & 2.445 & 62.10 \\
\hline 11 & 3 & 3.042 & 77.27 \\
\hline 12 & $31 / 2$ & 3.521 & 89.43 \\
\hline 13 & 4 & 3.998 & 101.55 \\
\hline 14 & 5 & 5.016 & 127.41 \\
\hline 15 & 6 & 6.031 & 153.19 \\
\hline 16 & 8 & 7.942 & 201.73 \\
\hline 17 & 10 & 9.976 & 253.39 \\
\hline 18 & 12 & 11.889 & 301.98 \\
\hline 19 & 14 & 13.073 & 332.05 \\
\hline 20 & 16 & 14.940 & 379.48 \\
\hline 21 & 18 & 61.809 & 426.95 \\
\hline 22 & 20 & 18.743 & 476.07 \\
\hline 23 & 24 & 22.544 & 572.62 \\
\hline
\end{tabular}

2.2.3: Water Demands: Fixtures and Fixture Units

The water distribution network supplies, at each delivery node (per hostel block), the following plumbing fixtures: 6 shower faucets, 8 bathroom sink faucets (lavatory sinks), 6 water closets with flush tanks, and 2 outdoor taps (hose bibs).Table 3 presents the water supply fixture units for estimation of water demand. 
Table 3: Water Supply Fixture Units (Uniform Plumbing Code, 2016)

\begin{tabular}{|c|c|c|c|c|}
\hline \multirow[t]{2}{*}{$\begin{array}{l}\text { Individual } \\
\text { Fixtures }\end{array}$} & \multicolumn{2}{|c|}{$\begin{array}{c}\text { Minimum Fixture Branch } \\
\text { Pipe Size }\end{array}$} & \multicolumn{2}{|c|}{ Water Supply Fixture Units WSFU } \\
\hline & (inch) & $(\mathrm{mm})$ & $\begin{array}{c}\text { Private } \\
\text { Installations }\end{array}$ & $\begin{array}{c}\text { Public } \\
\text { Installations }\end{array}$ \\
\hline Bathtub & $1 / 2$ & 15 & 4 & 4 \\
\hline Bathtub with $3 / 4$ " valve & $3 / 4$ & 20 & 10 & 10 \\
\hline Bidet & $1 / 2$ & 15 & 1 & \\
\hline Dishwasher, domestic & $1 / 2$ & 15 & 1.5 & 1.5 \\
\hline Drinking fountain & $1 / 2$ & 15 & 0.5 & 0.5 \\
\hline Hose bib & $1 / 2$ & 15 & 0.5 & 2.5 \\
\hline Lavatory & $1 / 2$ & 15 & 1 & 1 \\
\hline Bar sink & $1 / 2$ & 15 & 1 & 2 \\
\hline Clinic faucet sink & $1 / 2$ & 15 & 3 & \\
\hline Kitchen sink, domestic & $1 / 2$ & 15 & 1.5 & 1.5 \\
\hline Laundry sink & $1 / 2$ & 15 & 1.5 & 1.5 \\
\hline Service or mop basin & $1 / 2$ & 15 & 1.5 & 3 \\
\hline Washup basin & $1 / 2$ & 15 & 2 & \\
\hline Shower head & $1 / 2$ & 15 & 2 & 2 \\
\hline Urinal with flush tank & $1 / 2$ & 15 & 2 & 2 \\
\hline Wash fountain & $3 / 4$ & 20 & 4 & \\
\hline Water closet with gravity tank & $1 / 2$ & 15 & 2.5 & 2.5 \\
\hline Water closet with flushometer tank & $1 / 2$ & 15 & 2.5 & 2.5 \\
\hline Water cooler & $1 / 2$ & 15 & 0.5 & 0.5 \\
\hline
\end{tabular}

Table 4 gives conversion of the total fixture units to flow rates

Table 4: Diversity Table for Demand in Water Supply Systems without Flush Valves (Uniform Plumbing Code, 2016)

\begin{tabular}{|c|c|c|c|}
\hline \multicolumn{5}{|c|}{ Demand } \\
\hline WSFU & GPM & $\mathrm{ft}^{3} / \min$ & $l / s$ \\
\hline 1 & 3 & 0.41 & 0.19 \\
\hline 2 & 5 & 0.68 & 0.32 \\
\hline 4 & 8 & 1.07 & 0.51 \\
\hline 8 & 12.8 & 1.71 & 0.81 \\
\hline 15 & 17.5 & 2.3 & 1.1 \\
\hline 30 & 23.3 & 3.1 & 1.5 \\
\hline 50 & 29.1 & 3.9 & 1.8 \\
\hline
\end{tabular}

\subsection{4: The Limiting Velocity Constraints}

As water flows through pipes of the network, undesirable noise would be produced if the velocity of the flow is high. Water hammer, cavitation and erosion of the pipe internal surface are also associated with high velocity of flow (Kocyigit et al, 2015). In order to reduce these negative effects, the maximum velocity of flow is limited according to the plumbing code employed. According to Uniform Plumbing Code (2016), the (maximum) pipe flow velocity should be no more than $2.44 \mathrm{~m} / \mathrm{s}$ (i.e. $8 \mathrm{ft} / \mathrm{s}$ ). Also, a minimum flow velocity sufficient to prevent possible flow stagnation, associated growth of sediments and pipe blockage, is required. In the work of Kocyigit et al (2015), a minimum velocity (known as flushing velocity) was set at $0.5 \mathrm{~m} / \mathrm{s}$. This is adopted as the lower limit for the pipe flow velocities in this work. Thus, the velocity limiting constraints is summarized as:

Lower velocity limit $=0.5 \mathrm{~m} / \mathrm{s} \leq \mathrm{v}_{\mathrm{j}} \leq 2.44 \mathrm{~m} / \mathrm{s}=$ Upper velocity limit

where

$v_{j}=$ velocity of flow in pipe $j$; for each $\mathrm{j}=1,2, \ldots, \quad \mathrm{NP}$

and $\mathrm{NP}=$ number of pipes in the network.

2.2.5: Nodal Pressure Limit

It is important to have sufficient discharge pressures at the delivery units, as this would allow for further interior plumbing extensions. If the pressure is not sufficient, the flow to indoor fixtures will be delivered at weak pressures. Also, water may not have sufficient pressure to rise through vertical pipes en route to fixtures. Hence, a minimum residual pressure is ensured at the delivery nodes of the network. This value is set at the node having the highest head loss (relative to source node). This node is known as the first index node. Uniform Plumbing Code (2016) stipulates a minimum residual pressure of $124.106 \mathrm{kPa}\left(12.6553 \mathrm{mH}_{2} \mathrm{O}\right.$ or $\left.18.0 \mathrm{psi}\right)$. 
2.2.6: Cross Sectional Area, Flow Rate and Reynolds Number

Area of cross-section of pipe $\quad \mathrm{A}=\frac{\pi}{4} D^{2}$

where $D=$ internal diameter of the pipe.

Volumetric flow rate (or discharge) $Q=A v$

where $v=$ velocity of fluid flow in pipe

and Reynolds number $\quad R e=\frac{\rho V D}{\mu}=\frac{4 Q}{\pi \eta D}$

where $\rho=$ density of water.

$$
\begin{aligned}
& \mu=\text { dynamic viscosity of fluid. } \\
& \eta=\text { kinematic viscosity of fluid }\left(=\frac{\mu}{\rho}\right)
\end{aligned}
$$

\subsection{7: Major Losses}

In this paper, major losses, which are losses due to friction, are computed using Darcy-Weisbach equation (Ideriah, 2017) given as

$$
h=K Q^{2}
$$

where $K=C_{f}\left(\frac{l}{D}\right)\left(\frac{32}{g \pi^{2} D^{4}}\right)$

$$
C_{f}=\text { fanning factor }
$$

To accommodate possible network solutions with some reversed (negative) flow directions, Darcy-Weisbach equation is modified as

$$
h=K Q|Q|
$$

2.2.8: Colebrook-White and Hagen-Poiseuille Equations

a. Colebrook-White Equation

For transitional and turbulent flow regimes, this equation combines the three parameters, $C_{f}, \operatorname{Re}$ and $(\bar{e} / D)$ into an implicit equation (in $C_{f}$ ) as

$$
\frac{1}{\sqrt{C_{f}}}+4 \log _{10}\left(\frac{\bar{e} / D}{3.71}+\frac{1.26}{R e \sqrt{C_{f}}}\right)=0
$$

for $R e>2100$, where $\bar{e}=$ absolute roughness of the pipe

b. Hagen-Poiseuille Equation

For laminar flow regimes,

$$
C_{f}=\frac{16}{R_{e}} ; R_{e}<2100
$$

2.2.9: Continuity Equation

Continuity equation is the fluid dynamics expression of the law of conservation of mass. It states that mass (or mass flow rate) is conserved. For a distribution network, the principle is applied to the nodes. For a steady state, incompressible fluid, at a given node $i$, the algebraic sum of the flow rates leaving and entering the node, with due regard to sign $(+/-)$, is zero:

$$
\sum Q_{j}=\left.0\right|_{i}
$$

where $\mathrm{j}$ is the pipe connected to the node $i$ and $Q_{j}$ is the flow rate in pipe $j$. This equation is applied on all nodes, except Node 1 . By reason of assigning signs (+/-) to each $Q_{j}$, the flow rates in the pipes can be estimated to be positive or negative, and these signs only depict direction of flow. The (initial) directions of the flow in the pipes are assumed before the computation. This initial assumption of direction facilitates the use of the continuity equation. Nevertheless, the signs (+/-) of the computed flow rates approve or disapprove the initial directions assumed. Thus, a positive (+) value endorses the assumed direction and a negative (-) value indicates a reverse direction.

2.2.10: Principle of Head Balance

The principle of head balance is a corollary of the principle of head identity, which states that the pressure of a fluid in a steady flow, at any fixed point, is constant, and independent of the path to the given point. Hence, the pressure difference between any two points (more interestingly, nodes) in a steady flow is constant. The head balance principle follows thus:

The algebraic sum of head losses, with due regard to sign, around any closed loop $L$ in a flow network, is zero:

$$
\sum h_{j}=0 \text { around any closed Loop L }
$$

where $j$ is a pipe with flow direction along the path of the closed loop $\mathrm{L}$ and $h_{j}$ is the total head loss through pipe $j$. This principle is applied on the "irreducible" loops and complements the continuity equations. Considering any two points 1 and 2 in the network, let $H_{2}$ and $H_{2}$ represent the respective (absolute) heads at those points; then, head loss between points 1 and $2, h=\Delta H_{1,2}=H_{1}-H_{2}$

In application of the head balance principle, points 1 and 2 coincide with immediate neighbour nodes, and the head 
loss between the nodes is the resulting head loss in the connecting pipe.

\subsubsection{1: Bernoulli's Equation}

This equation relates flow parameters of two separate points in a steady flow, expressed as the conservation of energy or head. For any two arbitrary points 1 and 2, Bernoulli's equation states that

$$
\frac{\mathrm{P}_{1}}{\rho g}+\frac{\mathrm{v}_{1}^{2}}{2 g}+\mathrm{z}_{1}=\frac{\mathrm{P}_{2}}{\rho g}+\frac{\mathrm{v}_{2}^{2}}{2 g}+\mathrm{z}_{2}+\mathrm{H}_{\text {total }}
$$

where $\mathrm{P}_{1}, \mathrm{P}_{2}=$ Pressures at points 1 and 2

$\mathrm{v}_{1}, \mathrm{v}_{2}=$ (average) velocities of fluid at points 1 and 2

$\mathrm{z}_{1}, \mathrm{z}_{2}=$ elevations of the fluid at points 1 and 2 from a chosen horizontal datum

$\mathrm{H}_{\text {total }}=$ the total head losses, major and minor, encountered in the path between 1 and 2 .

2.2.12: Newton-Raphson Univariable Algorithm

This numerical iterative method extracts roots from implicit equations which defy the analytical approach. It is employed in this study in obtaining $C_{f}$ in Colebrook-White equation. The Newton-Raphson univariate iterative formula for solving the equation $F(y)=0$ is given as (Riley et al, 2006)

$$
y_{n+1}=y_{n}-\frac{F\left(y_{n}\right)}{F^{\prime}\left(y_{n}\right)} \text { for } \mathrm{n}=0,1,2,3, \ldots
$$

where $y_{0}=$ initial guess, and $F^{\prime}\left(y_{0}\right) \neq 0$

From Eqn. 6 (Colebrook-White equation)

$$
\begin{gathered}
F\left(C_{f i}\right)=\frac{1}{\sqrt{C_{f i}}}+4 \log _{10}\left(\frac{\bar{e} / D}{3.71}+\frac{1.26}{R e \sqrt{C_{f i}}}\right)=0 \\
\therefore F^{\prime}\left(C_{f i}\right)=\frac{\partial F}{\partial C_{f i}}=-\frac{1}{2} C f_{i}^{-\frac{3}{2}}\left[1+\frac{5.04 \log _{10} e}{\left.\left(\frac{\bar{e} / D}{3.71}+\frac{1.26}{R e \sqrt{C_{f i}}}\right) \operatorname{Re}\right]}\right.
\end{gathered}
$$

where $e=$ the base of natural logarithm $\cong 2.7181$.

The Newton-Raphson univariate iterative formula is thus

$$
C_{f i+1}=C f_{i}-\frac{{ }^{F}\left(c_{f i}\right)}{F^{\prime}\left(c_{f i}\right)}
$$

The resulting iterative equation for evaluating $C_{f i+1}$ is derived as

$$
\begin{aligned}
C_{f i+1} & =\frac{C_{f i}}{\left(1+x_{i} / R e\right.}\left[3+\frac{x_{i}}{R e}+8 \times \sqrt{C_{f i}} \times \log _{10}\left(\frac{5.04}{x_{i}} \log _{10} e\right)\right] \\
\text { where } \quad x_{i} & =\frac{5.04 \log _{10} e}{\left(\frac{\bar{e} / D}{3.71}+\frac{1.26}{R e}\right)}
\end{aligned}
$$

for $\mathrm{i}=0,1,2,3, \ldots$ and $C_{f 0}=\left.C_{f i}\right|_{i=0}$ is some initial guess.

\subsubsection{3: Newton-Raphson Multivariable Method}

The algorithm of Newton-Raphson multivariable technique is used to solve the generated system of non-linear equations for values of flow rates and then, by extension, head losses, frictional factors $\left(C_{f}\right)$ and other parameters. It is noteworthy that this algorithm is executed at fixed diameters of the pipes. So the algorithm is not used to size pipes, and as such does not, per se, resolve the velocity limiting problem. This algorithm is thus embedded in a broader algorithm for pipe-sizing. The sequence of steps which constitute the Newton-Raphson algorithm follows thus:

Step1 : Obtain the system of equations by applying continuity Eqn. 8 on all nodes except Node 1,

$$
\sum_{j} Q_{j}=\left.0\right|_{i=2,3, \ldots, N N}
$$

where $\mathrm{NN}=$ number of nodes and $i$ indexes each node. This yields the following equations for the respective nodes:

$$
\begin{array}{r}
Q_{1}-Q_{2}-Q_{2}=0 \ldots \ldots \ldots \ldots \ldots \ldots \text { Node } 2 \\
Q_{2}-Q_{3}-Q_{6}-Q_{3}=0 \ldots \ldots \ldots \ldots \text { Node } 3 \\
Q_{3}-Q_{4}-Q_{4}=0 \ldots \ldots \ldots \ldots \ldots \ldots \ldots \text { Node } 4 \\
Q_{4}-Q_{5}-Q_{7}-Q_{5}=0 \ldots \ldots \ldots \ldots \text { Node } 5 \\
Q_{5}-Q_{8}-Q_{6}=0 \ldots \ldots \ldots \ldots \ldots \ldots \ldots \text { Node } 6 \\
Q_{9}-Q_{10}-Q_{7}=0 \ldots \ldots \ldots \ldots \ldots \ldots \text { Node } 7 \\
Q_{6}+Q_{10}-Q_{11}-Q_{8}=0 \ldots \ldots \ldots \text { Node } 8 \\
Q_{11}-Q_{12}-Q_{9}=0 \ldots \ldots \ldots \ldots \ldots \text { Node } 9
\end{array}
$$




$$
\begin{aligned}
& Q_{7}+Q_{12}-Q_{13}-Q_{10}=0 \ldots \ldots \ldots \text { Node } 10 \\
& Q_{8}+Q_{13}-Q_{11}=0 \ldots \ldots \ldots \ldots \ldots \text { Node } 11
\end{aligned}
$$

where $\mathrm{Qd}_{\mathrm{i}}=$ delivery (consumption) rate at Node $\mathrm{i}$.

Here, in the case of same delivery rates,

$\mathrm{Qd}_{\mathrm{i}}=\mathrm{Qd}_{\mathrm{k}}$ for all $\mathrm{i} \& \mathrm{k}(\mathrm{i} \neq 1 \neq \mathrm{k}) ; \mathrm{i}, \mathrm{k}=2,3, \ldots, 11$ (that is, except the source Node 1$)$.

Now applying the head balance principle Eq. 9 on all "irreducible" loops:

$$
\sum_{i} h_{j}=\left.0\right|_{i=1,2,3, \ldots, N L}
$$

where NL $=$ No. of "irreducible" loops, $i$ indexes each such loop. Here, "irreducible" implies not containing a smaller loop within. So, $(\mathrm{NN}-1)+\mathrm{NL}=\mathrm{NP}$ for consistency of system of equations; where $\mathrm{NP}=\mathrm{No}$ of pipes in the loop with unknown flow rates.

Since $h=k|Q| Q$, then

$$
\sum_{i} K_{i} Q_{i}\left|Q_{i}\right|=\left.0\right|_{i=1,2,3, \ldots, N L}
$$

The incorporation of these equations constitutes a non-linear system of equations.

From the three loops (head balance principle):

Loop 1: Nodes 1-2-3-8-7-1, Loop 2: Nodes 3-4-5-10-9-8-3, and Loop 3: Nodes 5-6-11-10-5 we have

$$
\begin{aligned}
& -K_{1} Q_{1}\left|Q_{1}\right|-K_{2} Q_{2}\left|Q_{2}\right|-K_{6} Q_{6}\left|Q_{6}\right|+K_{10} Q_{10}\left|Q_{10}\right|+K_{9} Q_{9}\left|Q_{9}\right|=0 \ldots \ldots \ldots \ldots \ldots \ldots \ldots \text { loop } 1 \\
& -K_{3} Q_{3}\left|Q_{3}\right|-K_{4} Q_{4}\left|Q_{4}\right|-K_{7} Q_{7}\left|Q_{7}\right|+K_{12} Q_{12}\left|Q_{12}\right|+K_{11} Q_{11}\left|Q_{11}\right|+K_{6} Q_{6}\left|Q_{6}\right|=0 \ldots \text { loop } 2 \\
& -K_{5} Q_{5}\left|Q_{5}\right|-K_{8} Q_{8}\left|Q_{8}\right|+K_{13} Q_{13}\left|Q_{13}\right|+K_{7} Q_{7}\left|Q_{7}\right|=0 \ldots \ldots \ldots \ldots \ldots \ldots \ldots \ldots \ldots \ldots \ldots \text { loop } 3
\end{aligned}
$$

Step 2: Introduce function $f(Q)$ into each equation such that

$$
f\left(\left.Q_{j}\right|_{j=1,2,3, \ldots, N P}\right)=\left.0\right|_{i=1,2,3, \ldots . . N P}
$$

and generate the Jacobian matrix $\mathrm{J}$, and the function vector $\mathrm{F}$ :

$$
J=\left[J_{i j}\right]_{N P \times N P} \text { and } F=\left\{f_{i}\right\}_{N P \times 1}
$$

where $J_{i j}$ is the element of $J$ at the $i^{\text {th }}$ row and $j^{\text {th }}$ column position and $f_{i}=i^{\text {th }}$ element in $F$ for each $i=1,2$, $3, \ldots, \mathrm{NP}$ and $j=1,2,3, \ldots, \mathrm{NP}$

The functions (and consequently, the function vector $\mathrm{F}$ ) are thus introduced into the equation system as follows:

$$
\begin{gathered}
f_{1}=Q_{1}-Q_{2}-Q d_{2} \\
f_{2}=Q_{2}-Q_{3}-Q_{6}-Q d_{3} \\
f_{3}=Q_{3}-Q_{4}-Q d_{4} \\
f_{4}=Q_{4}-Q_{5}-Q_{7}-Q d_{5} \\
f_{5}=Q_{5}-Q_{8}-Q d_{6} \\
f_{6}=Q_{9}-Q_{10}-Q d_{7} \\
f_{7}=Q_{6}+Q_{10}-Q_{11}-Q d_{8} \\
f_{8}=Q_{11}-Q_{12}-Q d_{9} \\
f_{9}=Q_{7}+Q_{12}-Q_{13}-Q d_{10} \\
f_{10}=Q_{8}+Q_{13}-Q d_{11} \\
f_{11}=-K_{1} Q_{1}\left|Q_{1}\right|-K_{2} Q_{2}\left|Q_{2}\right|-K_{6} Q_{6}\left|Q_{6}\right|+K_{10} Q_{10}\left|Q_{10}\right|+K_{9} Q_{9}\left|Q_{9}\right| \\
f_{12}=-K_{3} Q_{3}\left|Q_{3}\right|-K_{4} Q_{4}\left|Q_{4}\right|-K_{7} Q_{7}\left|Q_{7}\right|+K_{12} Q_{12}\left|Q_{12}\right|+K_{11} Q_{11}\left|Q_{11}\right|+K_{6} Q_{6}\left|Q_{6}\right| \\
f_{13}=-K_{5} Q_{5}\left|Q_{5}\right|-K_{8} Q_{8}\left|Q_{8}\right|+K_{13} Q_{13}\left|Q_{13}\right|+K_{7} Q_{7}\left|Q_{7}\right| \\
\text { with } K_{j}=C f_{j}\left(\frac{l_{j}}{D_{j}}\right)\left(\frac{32}{g \pi^{2} D_{j}^{4}}\right) ; j=1,2, \ldots, 13 \text { (for each pipe } j \text { ) }
\end{gathered}
$$

The Jacobian matrix $J$ is thus defined as :

$\mathrm{J}=\left[J_{i j}\right]$, where $J_{i j}=\frac{\partial f_{i}}{\partial Q_{j}}=$ element of $j$ at the $i^{\text {th }}$ row and $j^{\text {th }}$ column, $i, j=1,2,3, \ldots, 13$.

The function vector $\mathrm{F}$ is defined as:

$F=\left\{f_{i}\right\}_{13 \times 1}$, where $f_{i}=i^{\text {th }}$ function defined in the system of equations as the $i^{\text {th }}$ row element in $F$, such that elements of vector $\mathrm{F}$ are the introduced functions, while elements of the Jacobian matrix $\mathrm{J}$ are obtained by differentiation.

$J_{i j}=\frac{\partial f_{i}}{\partial Q_{j}}=\left\{\begin{array}{c}0, \quad \text { if pipe } j \text { is not connected to node } i+1 \text { at either ends } \\ \pm 1, \quad \text { if pipe } j \text { is connected to node } i+1 \text { at one of its ends }\end{array}\right\} i<N N$ 
where

$d H Q_{j}$

$=\left\{\begin{array}{l}\frac{1}{2} \text {, if flow in pipe } j \text { in loop } i-N N+1 \text { is laminar at the instant of iteration } \\ \frac{1}{1+\mathrm{X}_{j} / R e_{j}} \text {, if flow in pipe } j \text { in loop } i-N N+1 \text { is turbulent/transitory at the instant of iteration }\end{array}\right.$ and

$$
x_{j}=\frac{5.04 \log _{10} e}{\frac{\bar{e} / D_{j}}{3.71}+\frac{1.26}{R e_{j} \sqrt{C f_{j}}}}
$$

The sign (+/-) in the expressions \pm 1 and $\pm 2 K_{j}\left|Q_{j}\right| d H Q_{j}$ are chosen based on the sign conventions employed, stated as follows:

For continuity equations $(i<N N)$

i) + : for flow rate with (assumed) direction running into the considered node.

ii) - : for flow rate with (assumed) direction leaving the considered node.

For head balance equations $(N N \leq i \leq N P)$

i) + : for head loss with (assumed) flow direction in counter direction to the loop direction taken.

ii) - : for head loss with (assumed) flow direction in same direction as the loop direction taken.

Step 3: Set-up the Newton-Raphson multivariable iterative matrix equation

$$
\mathrm{J} \times \Delta \mathrm{Q}=-\mathrm{F}
$$

The iterative matrix equation is set up thus:

$$
\left[\begin{array}{ccccc}
J_{11} & J_{12} & J_{13} & \cdots & J_{1 N P} \\
J_{21} & J_{22} & J_{23} & \cdots & J_{2 N P} \\
J_{31} & J_{32} & J_{33} & \cdots & J_{3 N P} \\
\vdots & \vdots & \vdots & \vdots & \vdots \\
J_{N P 1} & J_{N P 2} & J_{N P 3} & \cdots & J_{N P N P}
\end{array}\right]\left\{\begin{array}{c}
\Delta Q_{1} \\
\Delta Q_{2} \\
\Delta Q_{3} \\
\vdots \\
\Delta Q_{N P}
\end{array}\right\}=-\left\{\begin{array}{c}
f_{1} \\
f_{2} \\
f_{3} \\
\vdots \\
f_{N P}
\end{array}\right\}
$$

where $\Delta Q$ is the column vector, $\left.\left\{\Delta Q_{i}\right\}\right|_{i=1,2,3, \ldots, N P}$ is the flow correction vector for each pipe flow rate, and the vector $Q=\left.\left\{Q_{i}\right\}\right|_{i=1,2,3, \ldots, N P}$ is a column vector of the flow rates.

Step 4: Take an initial guess for Q (i.e. initial guesses for all flow rates) and substitute into J and -F of Eqn. 14. Step 5: Solve the linear system resulting from Step 4 for the $\Delta Q \mathrm{~s}$

Step 6: Modify each flow rate (initial guess) by adding the computed correction flow rates.

The modified flow rates which are to be used in the next iteration are obtained as

$$
\text { Modified flow rate } Q_{j}{ }^{\prime}=\Delta Q_{j}+Q_{j} \text { for each } j=1,2,3, \ldots, N P
$$

Step 7: Replace previous flow rates (initial guesses) with $Q_{j}{ }^{\prime}$ in Step 4 and follow through to Step 6. Repeat until convergence or desired degree of accuracy is obtained.

2.2.14: Algorithm for Pipe Size Selection in the Distribution Network

The principle of pipe sizing in distribution network rests on the velocity limiting constraints (and/or available head constraint). Thus, an algorithm for tackling the velocity constraint, which also satisfies the system equations, is required.

a) The pipe-sizing model

The incorporation of the non-linear equations of the network and the velocity limiting constraints re-formulates the network problem.

Thus, $f_{i}\left(Q_{1}, Q_{2}, Q_{3}, \ldots, Q_{13}, D_{1}, D_{2}, D_{3}, \ldots D_{13}\right)=0 ; i=1,2,3, \ldots, 13$

subject to $0<a \leq \frac{4\left|\mathrm{Q}_{\mathrm{j}}\right|}{\pi D_{j}^{2}} \leq b$ and $D_{j} \in S$,

where $a$ and $b$ are constants defining the acceptable lower and upper flow velocity limits, the expression $\frac{4\left|\mathrm{Q}_{j}\right|}{\pi D_{j}^{2}}$ is the magnitude of the fluid velocity in pipe $j$, and $S=$ set of standard pipe sizes for each $j=1,2,3, \ldots, 13$. The equations $f_{i}=0 ; i=1,2,3, \ldots, 13$ constitute the system of equations obtained from the network as generated by applying continuity and head balance principles.

b) Initial guess variation

The solution set obtained by iterative methods usually depends on the initial guesses made. Knowledge of this instructs that if several sets of solutions are to be obtained, the iterative algorithm is to be repeated at different initial guesses. The pipe-sizing algorithm created in this work utilizes the idea of varying initial values of diameters for producing many possible solution sets. The values of the diameters are restricted to standard stock values, both in initial guesses and in the corrective steps. 
c) Pipe size correction technique

This pipe-sizing algorithm utilizes the principle that when a pipe flow fails to meet the velocity constraints, the pipe size is adjusted, and not its flow rate. The pipe re-sizing procedure is as follows:

1) If velocity meets constraint (i.e. velocity is within range), the diameter is unaltered.

2) If velocity is greater than the upper limit (velocity is "too high"), diameter is increased to the next larger standard stock size.

3) If velocity is lower than the lower limit (velocity is "too low"), diameter is reduced to next smaller size.

4) If a pipe in case (2) already has the largest pipe size, or a pipe in case (3) already has the smallest pipe size, the pipe size is left unaltered.

5) If scenario (4) plays out to exactly the same pipes in two (or more) subsequent re-sizing iterations, "degeneracy" can be said to have occurred. The algorithm proceeds thereafter by using a different set of initial values for the diameters.

Thus, for any set of initial diameters used, either a solution (to the pipe sizing problem) or degeneracy results. When the diameters have been decided or adjusted, then Newton-Raphson method is employed to deduce the corresponding flow rates in the pipes. The algorithm for pipe-sizing the network is as demonstrated in the flow chart of Fig. 2.

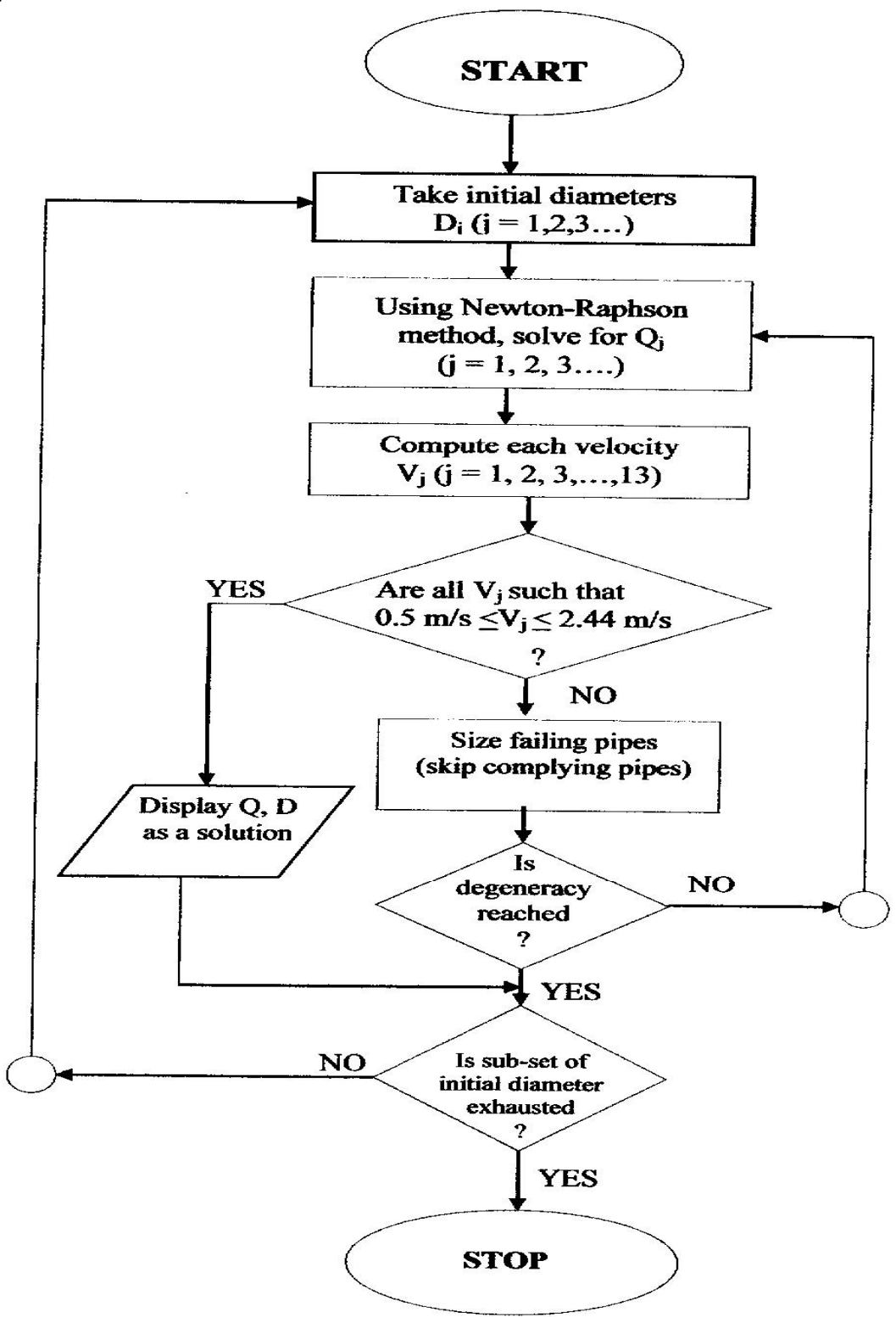

Fig. 2: Pipe sizing algorithm

The network solution (with its pipe selection) with the least pressure loss at its first index node is selected (for tank elevation, and subsequently, pump power optimization). 
2.2.15: Adopted Technique/Algorithm for Initializing Pipe Diameters

The initialization of the diameters can be done arbitrarily. Nevertheless, the following steps are adopted in this work:

1) Arrange the standard pipe sizes in ascending order as set $\mathrm{S}^{(1)}$, and descending order as set $\mathrm{S}^{(2)}$. Also arrange the set of network pipes in ascending order of their numbering, and say set $P$.

2) For each value of $\mathrm{r}=1$ and 2 , in turns (beginning with $r=1$ ), let $S_{i}^{r}$ represent the $i^{\text {th }}$ entry of the ordered set $S^{(r)}$, and $N=$ cardinality of set $S^{(r)}$. Let $p_{j}$ represent the $j^{\text {th }}$ entry of set $P$ and $N_{p}=$ cardinality of set $P$

3) With a given $r$, set $k=1,2,3 \ldots, N_{p}$ (beginning with $k=1$ ), and for a given $k$, set $i=1,2,3 \ldots N_{p}$ (beginning with $i=1$ and in increasing order):

Generate the ordered subset $S S_{k / i}^{r}$ as

$S S_{k / i}^{r}=\left\{S_{i}^{r}, S_{i+1}^{r}, S_{i+2}^{r}, \ldots, S_{i+k-1}^{r}\right\}=\left\{S_{n}^{r}\right\}_{n=i}^{i+k-1}$

where $S_{n}^{r}(i \leq n \leq(i+k-1))$ is the $n^{\text {th }}$ member of the ordered set $S^{r}$

Now, let $S S_{m}$ represent the $m^{\text {th }}$ member of ordered set $S S_{k / i}^{r}(1 \leq m \leq k)$

4) For each $j=1,2,3, \ldots, 13$

i) For $1 \leq j \leq k$

Assign diameter $S S_{j}$ to pipe $p_{j}$

ii) For $j>\mathrm{k}$

Assign diameter $S S_{j^{\prime}}$ to pipe $p_{j}$

where $j \equiv j^{\prime}(\bmod k)$ and $0<j^{\prime} \leq k$ and $\bmod k$ interpretes as modulus of $k$.

2.2.16: Tank (Reservoir) Elevation

The tank and pump are arranged as shown in Fig 3.

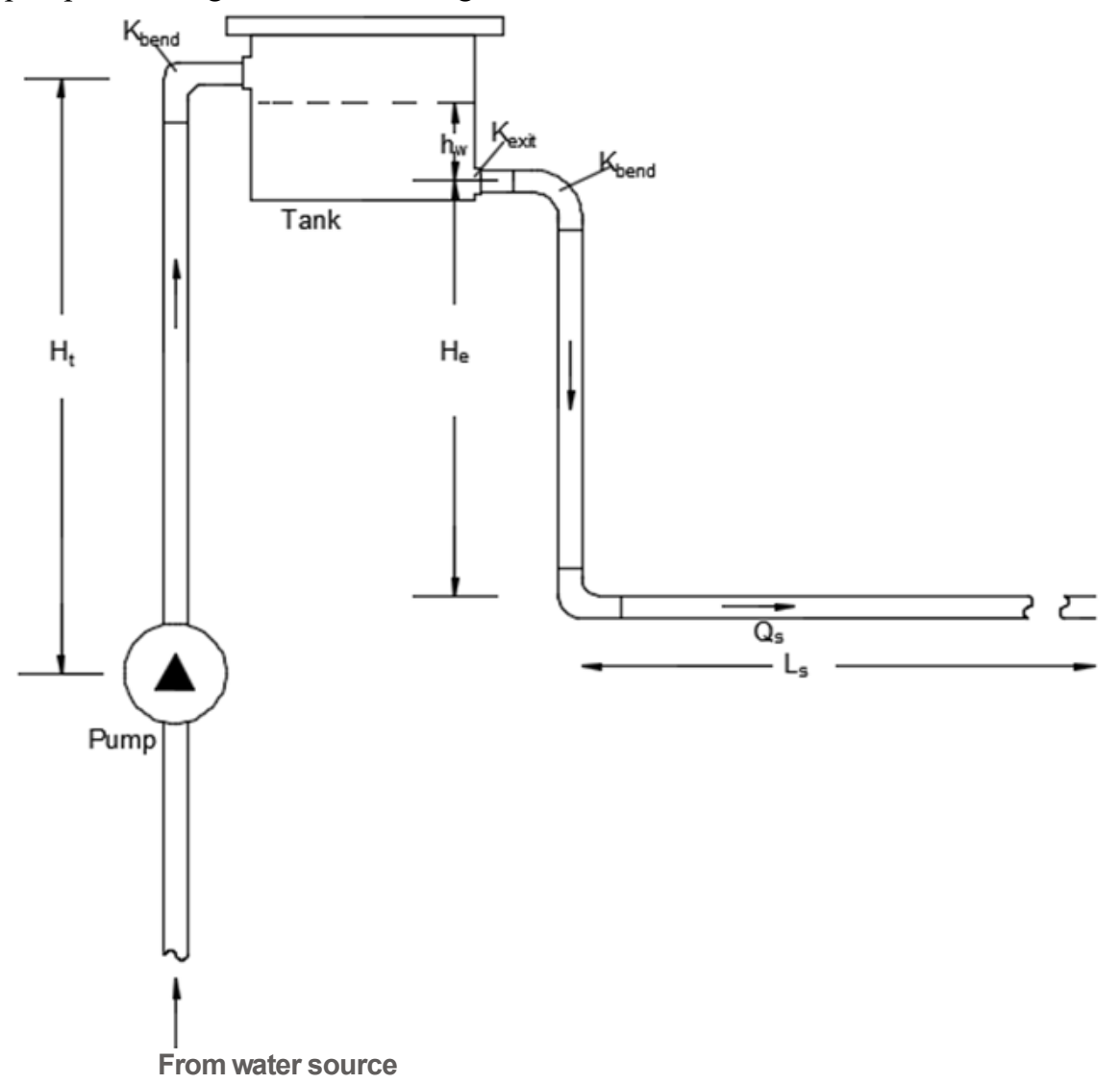

Fig. 3: Pump, reservoir and transmission line arrangement Applying Bernoulli's principle at the tank exit and the network supply node:

$\left(\frac{P_{0}+\rho g h_{w}}{\rho g}\right)+\frac{1}{2 g} V_{e}^{2}+H_{e}=\frac{P_{s}}{\rho g}+\frac{1}{2} V_{s}^{2}+h_{\text {exit }}+h_{\text {bend } 1}+h f_{\text {He }}+h_{\text {bend } 2}+h_{L}+h_{\text {tee }}$ 
where

$P_{0}=$ Pressure of air at free surface.

$h_{\text {exit }}=$ head loss at tank exit

$h_{\text {bend } 1}, h_{\text {bend } 2}=$ head losses at the $90^{\circ}$ elbows

$h f_{H e}, h_{L}=$ frictional losses along pipe lengths $\mathrm{H}_{e}$ and $L$

$h_{\text {tee }}=$ head loss at the tee - junction of the transmission line

$h_{w}=$ height of water free surface from tank exit

$H_{e}=$ tank elevation; as height of tank exit from the transmission line.

Since a uniform cross-section pipe is used for the transmission,

$$
V_{e}=V_{s}=V
$$

$$
\text { With } \begin{aligned}
V^{2} & =\frac{16 Q_{i n}^{2}}{\pi^{2} D^{4}} \\
h_{\text {bend } 1} & =K_{\text {bend } 1} \frac{V^{2}}{2 g} \\
h_{\text {bend } 2} & =K_{\text {bend } 2} \frac{V^{2}}{2 g} \\
h f_{H_{e}} & =C f\left(\frac{H_{e}}{D}\right)\left(\frac{32}{g \pi^{2} D^{4}}\right) Q_{i n}^{2} \\
h f_{L} & =C f\left(\frac{L_{s}}{D}\right)\left(\frac{32}{g \pi^{2} D^{4}}\right) Q_{\text {in }}^{2} \\
h_{\text {tee }} & =K_{\text {tee }} \frac{V^{2}}{2 g}
\end{aligned}
$$

In order to meet the requirement of minimum residual pressure (at first index node)

$P_{s}=P_{s, \min }$ (pressure at source node when first index node is at minimal residual pressure)

$P_{0} \approx 0$ (atmospheric)

$h_{w}=0$ (water level at lowest)

$\therefore \quad H_{e}=\frac{P_{s, \min }}{\rho g}+h_{\text {exit }}+h_{\text {bend } 1}+h f_{\text {He }}+h_{\text {bend } 2}+h f_{L}+h_{\text {tee }}$

From Eqns 18, 19, 20, 21, 22, 23 and 24, making $H_{e}$ subject of formula (from the $H_{e}$ and $h f_{H e}$ terms)

$$
H_{e}=\frac{\frac{P_{s, \min }}{\rho g}+\frac{8 K_{\text {exit }} Q_{i n}^{2}}{g \pi^{2} D^{4}}+\frac{8 K_{\text {bend } 1} Q_{i n}^{2}}{g \pi^{2} D^{4}}+\frac{8 K_{\text {bend } 2} Q_{i n}^{2}}{g \pi^{2} D^{4}}+C f\left(\frac{L_{s}}{D}\right)\left(\frac{32}{g \pi^{2} D^{4}}\right) Q_{i n}^{2}+\frac{8 K_{t e e} Q_{i n}^{2}}{g \pi^{2} D^{4}}}{\left(1-C f\left(\frac{1}{D}\right)\left(\frac{32}{g \pi^{2} D^{4}}\right) Q_{i n}^{2}\right)}
$$

The tank elevation is affected by the horizontal displacement of the tank from the network (source node) and this displacement is denoted $L_{s}$. The distance $L_{s}$ can be taken at any convenient value on account of space constraints. Although, a zero value for $L_{s}$ optimizes tank elevation, it is considered as $50 \mathrm{~m}$ in this study. The minor loss coefficients used in computing the tank elevation are stated in Table 5.

Table 5: Minor loss coefficients

\begin{tabular}{|c|l|c|}
\hline $\mathbf{S} / \mathbf{N}$ & \multicolumn{1}{|c|}{ Type of fitting and form } & $K$ \\
\hline 1 & Pipe entry & 0.5 \\
\hline 2 & Pipe exit & 1.0 \\
\hline 3 & $90^{0}$ elbow bend (flanged) & 0.3 \\
\hline 4 & Tee (flanged) & 1.0 \\
\hline
\end{tabular}

A minimal height is computed for by using the available standard pipe diameter(s) that meets the velocity constraints $\left(0.5 m / s \leq \frac{4\left|\mathrm{Q}_{\mathrm{j}}\right|}{\pi D_{j}^{2}} \leq 2.44 \mathrm{~m} / \mathrm{s}\right)$ which results in a minimum positive value of $H_{e}$ in Eqn. 25 .

\section{Results and Discussions}

The polyvinyl chloride pipe used in the study has an absolute roughness, $\bar{e}=0.0015 \mathrm{~mm}$ (Engineering Encyclopedia, 2011). The hydraulic load (water demand) per delivery node (block) of the network is estimated in Tables 6 using data from Tables 3 and 4.

Table 6: Fixture Unit Evaluation

\begin{tabular}{|c|c|c|c|c|}
\hline S/N & Fixture type & Quantity & Fixture Unit & Total unit for each fixture type \\
\hline 1 & Shower faucet & 6 & 2.0 & 12.0 \\
\hline 2 & Lavatory sink & 8 & 1.0 & 8.0 \\
\hline 3 & Water closet & 6 & 2.5 & 15.0 \\
\hline 4 & Outdoor tap (hose bib) & 2 & 2.5 & 5.0 \\
\hline \multicolumn{4}{|l}{} & $\Sigma=40.0$ \\
\hline
\end{tabular}

Thus, a total of 40 water supply fixture (WSF) units is estimated. From Table 4, by linear interpolation, hydraulic load per hostel block $Q_{d}=26.2 \mathrm{gal} / \mathrm{min}=0.001655 \mathrm{~m}^{3} / \mathrm{s}$ 
$\therefore$ total flow rate supplied from tank to network (through supply Node 1 ) is $\mathrm{Q}_{\text {in }}=\Sigma \mathrm{Q}_{\mathrm{d}}$

$$
=0.01655 \mathrm{~m}^{3} / \mathrm{s} \text {. }
$$

Two typical sets of results from over 255 network solutions of flow rates and pipe sizes obtained by the developed algorithm (executed in MATLAB codes) are displayed:

\section{Result Set 1}

For Pipe 1, Diameter $=0.034544 \mathrm{~m}$, Flow-rate $=0.00199528 \mathrm{~m}^{\wedge} 3 / \mathrm{s}$, Headloss $=4.86788 \mathrm{~m}$, and Velocity $=$ $2.12897 \mathrm{~m} / \mathrm{s}$ (Turbulent Flow)

For Pipe 2, Diameter $=0.0261366 \mathrm{~m}$, Flow-rate $=0.000340281 \mathrm{~m}^{\wedge} 3 / \mathrm{s}$, Headloss $=0.682979 \mathrm{~m}$, and Velocity $=$ $0.634233 \mathrm{~m} / \mathrm{s}$ (Turbulent Flow)

For Pipe 3, Diameter $=0.0120142 \mathrm{~m}$, Flow-rate $=0.000154994 \mathrm{~m}^{\wedge} 3 / \mathrm{s}$, Headloss $=6.95355 \mathrm{~m}$, and Velocity $=$ $1.36721 \mathrm{~m} / \mathrm{s}$ (Turbulent Flow)

For Pipe 4, Diameter $=0.034544 \mathrm{~m}$, Flow-rate $=-0.00150001 \mathrm{~m}^{\wedge} 3 / \mathrm{s}$, Headloss $=-2.48859 \mathrm{~m}$, and Velocity $=$ $1.60051 \mathrm{~m} / \mathrm{s}$ (Turbulent Flow)

For Pipe 5, Diameter $=0.0261366 \mathrm{~m}$, Flow-rate $=-0.000915378 \mathrm{~m}^{\wedge} 3 / \mathrm{s}$, Headloss $=-3.925 \mathrm{~m}$, and Velocity $=$ $1.70613 \mathrm{~m} / \mathrm{s}$ (Turbulent Flow)

For Pipe 6, Diameter $=0.040386 \mathrm{~m}$, Flow-rate $=-0.00146971 \mathrm{~m}^{\wedge} 3 / \mathrm{s}$, Headloss $=-3.05756 \mathrm{~m}$, and Velocity $=$ $1.14731 \mathrm{~m} / \mathrm{s}$ (Turbulent Flow)

For Pipe 7, Diameter $=0.040386 \mathrm{~m}$, Flow-rate $=-0.00223963 \mathrm{~m}^{\wedge} 3 / \mathrm{s}$, Headloss $=-6.4859 \mathrm{~m}$, and Velocity $=$ $1.74833 \mathrm{~m} / \mathrm{s}$ (Turbulent Flow)

For Pipe 8 , Diameter $=0.0519938 \mathrm{~m}$, Flow-rate $=-0.00257038 \mathrm{~m}^{\wedge} 3 / \mathrm{s}$, Headloss $=-2.47058 \mathrm{~m}$, and Velocity $=$ $1.21061 \mathrm{~m} / \mathrm{s}$ (Turbulent Flow)

For Pipe 9, Diameter $=0.101549 \mathrm{~m}$, Flow-rate $=0.0145547 \mathrm{~m}^{\wedge} 3 / \mathrm{s}$, Headloss $=1.26181 \mathrm{~m}$, and Velocity $=1.79705$ $\mathrm{m} / \mathrm{s}$ (Turbulent Flow)

For Pipe 10, Diameter $=0.0894334 \mathrm{~m}$, Flow-rate $=0.0128997 \mathrm{~m}^{\wedge} 3 / \mathrm{s}$, Headloss $=1.23149 \mathrm{~m}$, and Velocity $=$ $2.05348 \mathrm{~m} / \mathrm{s}$ (Turbulent Flow)

For Pipe 11, Diameter $=0.0894334 \mathrm{~m}$, Flow-rate $=0.00977501 \mathrm{~m}^{\wedge} 3 / \mathrm{s}$, Headloss $=0.746284 \mathrm{~m}$, and Velocity $=$ $1.55606 \mathrm{~m} / \mathrm{s}$ (Turbulent Flow)

For Pipe 12, Diameter $=0.101549 \mathrm{~m}$, Flow-rate $=0.00812001 \mathrm{~m}^{\wedge} 3 / \mathrm{s}$, Headloss $=0.290342 \mathrm{~m}$, and Velocity $=$ $1.00257 \mathrm{~m} / \mathrm{s}$ (Turbulent Flow)

For Pipe 13, Diameter $=0.101549 \mathrm{~m}$, Flow-rate $=0.00422538 \mathrm{~m}^{\wedge} 3 / \mathrm{s}$, Headloss $=0.0903151 \mathrm{~m}$, and Velocity $=$ $0.521702 \mathrm{~m} / \mathrm{s}$ (Turbulent Flow)

\section{Result Set 2:}

For Pipe 1, Diameter $=0.0204216 \mathrm{~m}$, Flow-rate $=0.000636592 \mathrm{~m}^{\wedge} 3 / \mathrm{s}$, Headloss $=7.87032 \mathrm{~m}$, and Velocity $=$ $1.94353 \mathrm{~m} / \mathrm{s}$ (Turbulent Flow)

For Pipe 2, Diameter $=0.0261366 \mathrm{~m}$, Flow-rate $=-0.00101841 \mathrm{~m}^{\wedge} 3 / \mathrm{s}$, Headloss $=-4.74693 \mathrm{~m}$, and Velocity $=$ $1.89816 \mathrm{~m} / \mathrm{s}$ (Turbulent Flow)

For Pipe 3, Diameter $=0.0261366 \mathrm{~m}$, Flow-rate $=0.000304486 \mathrm{~m}^{\wedge} 3 / \mathrm{s}$, Headloss $=0.562191 \mathrm{~m}$, and Velocity $=$ $0.567518 \mathrm{~m} / \mathrm{s}$ (Turbulent Flow)

For Pipe 4, Diameter $=0.040386 \mathrm{~m}$, Flow-rate $=-0.00135051 \mathrm{~m}^{\wedge} 3 / \mathrm{s}$, Headloss $=-0.976853 \mathrm{~m}$, and Velocity $=$ $1.05426 \mathrm{~m} / \mathrm{s}$ (Turbulent Flow)

For Pipe 5, Diameter $=0.040386 \mathrm{~m}$, Flow-rate $=-0.000793744 \mathrm{~m}^{\wedge} 3 / \mathrm{s}$, Headloss $=-0.381219 \mathrm{~m}$, and Velocity $=$ $0.619625 \mathrm{~m} / \mathrm{s}$ (Turbulent Flow)

For Pipe 6, Diameter $=0.062103 \mathrm{~m}$, Flow-rate $=-0.00297789 \mathrm{~m}^{\wedge} 3 / \mathrm{s}$, Headloss $=-1.37166 \mathrm{~m}$, and Velocity $=$ $0.983092 \mathrm{~m} / \mathrm{s}$ (Turbulent Flow)

For Pipe 7, Diameter $=0.062103 \mathrm{~m}$, Flow-rate $=-0.00221177 \mathrm{~m}^{\wedge} 3 / \mathrm{s}$, Headloss $=-0.807535 \mathrm{~m}$, and Velocity $=$ $0.730172 \mathrm{~m} / \mathrm{s}$ (Turbulent Flow)

For Pipe 8 , Diameter $=0.0772668 \mathrm{~m}$, Flow-rate $=-0.00244874 \mathrm{~m}^{\wedge} 3 / \mathrm{s}$, Headloss $=-0.340576 \mathrm{~m}$, and Velocity $=$ $0.522237 \mathrm{~m} / \mathrm{s}$ (Turbulent Flow)

For Pipe 9, Diameter $=0.101549 \mathrm{~m}$, Flow-rate $=0.0159134 \mathrm{~m}^{\wedge} 3 / \mathrm{s}$, Headloss $=1.48289 \mathrm{~m}$, and Velocity $=1.96481$ $\mathrm{m} / \mathrm{s}$ (Turbulent Flow)

For Pipe 10, Diameter $=0.127406 \mathrm{~m}$, Flow-rate $=0.0142584 \mathrm{~m}^{\wedge} 3 / \mathrm{s}$, Headloss $=0.268834 \mathrm{~m}$, and Velocity $=$ $1.1184 \mathrm{~m} / \mathrm{s}$ (Turbulent Flow)

For Pipe 11, Diameter $=0.153187 \mathrm{~m}$, Flow-rate $=0.00962551 \mathrm{~m}^{\wedge} 3 / \mathrm{s}$, Headloss $=0.0548416 \mathrm{~m}$, and Velocity $=$ $0.522261 \mathrm{~m} / \mathrm{s}$ (Turbulent Flow)

For Pipe 12, Diameter $=0.127406 \mathrm{~m}$, Flow-rate $=0.00797051 \mathrm{~m}^{\wedge} 3 / \mathrm{s}$, Headloss $=0.0946257 \mathrm{~m}$, and Velocity $=$ $0.625193 \mathrm{~m} / \mathrm{s}$ (Turbulent Flow)

For Pipe 13, Diameter $=0.101549 \mathrm{~m}$, Flow-rate $=0.00410374 \mathrm{~m}^{\wedge} 3 / \mathrm{s}$, Headloss $=0.0857399 \mathrm{~m}$, and Velocity $=$ 
$0.506684 \mathrm{~m} / \mathrm{s}$ (Turbulent Flow)

The optimal network solution set is selected as the network solution with the least first index node pressure. It is worthwhile to note that the first index node varies from one solution set to another. Tables 7(a) and 7(b) show the optimal results.

Table 7(a): Optimal solution of network with assumed flow directions

\begin{tabular}{|c|c|c|c|c|l|}
\hline Pipe & $\begin{array}{c}\text { Diameter (D) } \\
(\mathrm{m})\end{array}$ & $\begin{array}{c}\text { Nominal size } \\
(\mathrm{inch})\end{array}$ & $\begin{array}{c}\text { Flow rate }(\mathrm{Q}) \\
\left(\mathrm{m}^{3} / \mathrm{s}\right)\end{array}$ & $\begin{array}{c}\text { Assumed node-node } \\
\text { direction }\end{array}$ & Flow type \\
\hline 1 & 0.062103 & $21 / 2$ & 0.0067375 & $1-2$ & turbulent \\
\hline 2 & 0.0519938 & 2 & 0.0050825 & $2-3$ & turbulent \\
\hline 3 & 0.0519938 & 2 & 0.00468377 & $3-4$ & turbulent \\
\hline 4 & 0.0519938 & 2 & 0.00302877 & $4-5$ & turbulent \\
\hline 5 & 0.0519938 & 2 & 0.00148161 & $5-6$ & turbulent \\
\hline 6 & 0.040386 & $11 / 2$ & -0.00125627 & $3-8$ & turbulent \\
\hline 7 & 0.0152908 & $1 / 2$ & -0.000107847 & $5-10$ & turbulent \\
\hline 8 & 0.0204216 & $3 / 4$ & -0.000173387 & $6-11$ & turbulent \\
\hline 9 & 0.0772668 & 3 & 0.0098125 & $1-7$ & turbulent \\
\hline 10 & 0.0772668 & 3 & 0.0081575 & $7-8$ & turbulent \\
\hline 11 & 0.062103 & $21 / 2$ & 0.00524623 & $8-9$ & turbulent \\
\hline 12 & 0.0519938 & 2 & 0.00359123 & $9-10$ & turbulent \\
\hline 13 & 0.040386 & $11 / 2$ & 0.00182839 & $10-11$ & turbulent \\
\hline
\end{tabular}

Table 7(b): Optimal solution of network with corrected flow directions

\begin{tabular}{|c|c|c|c|c|c|}
\hline Pipe & $\begin{array}{c}\text { Diameter (D) } \\
(\mathrm{m})\end{array}$ & $\begin{array}{l}\text { Nominal sizes } \\
\text { (inch) }\end{array}$ & $\begin{array}{c}\text { Flow rate }(\mathrm{Q}) \\
\left(\mathrm{m}^{3} / \mathrm{s}\right)\end{array}$ & $\begin{array}{c}\text { Actual node-node } \\
\text { direction }\end{array}$ & Flow type \\
\hline 1 & 0.062103 & $21 / 2$ & 0.0067375 & $1-2$ & turbulent \\
\hline 2 & 0.0519938 & 2 & 0.0050825 & $2-3$ & turbulent \\
\hline 3 & 0.0519938 & 2 & 0.00468377 & $3-4$ & turbulent \\
\hline 4 & 0.0519938 & 2 & 0.00302877 & $4-5$ & turbulent \\
\hline 5 & 0.0519938 & 2 & 0.00148161 & $5-6$ & turbulent \\
\hline 6 & 0.040386 & $1 \frac{1}{2}$ & 0.00125627 & $8-3$ & turbulent \\
\hline 7 & 0.0152908 & $1 / 2$ & 0.000107847 & $10-5$ & turbulent \\
\hline 8 & 0.0204216 & $3 / 4$ & 0.000173387 & $11-6$ & turbulent \\
\hline 9 & 0.0772668 & 3 & 0.0098125 & $1-7$ & turbulent \\
\hline 10 & 0.0772668 & 3 & 0.0081575 & $7-8$ & turbulent \\
\hline 11 & 0.062103 & $2 \frac{1}{2}$ & 0.00524623 & $8-9$ & turbulent \\
\hline 12 & 0.0519938 & 2 & 0.00359123 & $9-10$ & turbulent \\
\hline 13 & 0.040386 & $1 \frac{1}{2}$ & 0.00182839 & $10-11$ & turbulent \\
\hline
\end{tabular}

The head losses at the nodes relative to Node 1 (source node) and the least nodal pressures in line with Uniform Plumbing Code (UPC) (2016) are given in Table 8.

Table 8: Head Losses (Assuming Negligible Minor Losses in Distribution Network)

\begin{tabular}{|c|l|l|}
\hline Node & Head losses differential to node 1 (metre) & \multicolumn{1}{c|}{$\begin{array}{c}\text { Absolute pressure } \\
\left(\text { in } \mathrm{mH}_{2} \mathrm{O}\right)\end{array}$} \\
\hline 1 & $1.4988 \mathrm{e}-15 \approx 0$ & $14.1634=P_{s, \min }$ \\
\hline 2 & 1.11279 & 13.0506 \\
\hline 3 & 0.740244 & 13.4232 \\
\hline 4 & 1.50818 (first index node) & 12.6553 (UPC minimum pressure) \\
\hline 5 & 1.23838 & 12.9251 \\
\hline 6 & 0.875311 & 13.2881 \\
\hline 7 & 0.199845 & 12.9636 \\
\hline 8 & 0.307516 & 12.8559 \\
\hline 9 & 0.361755 & 13.8017 \\
\hline 10 & 0.455124 & 13.7083 \\
\hline 11 & 0.540061 & 13.6234 \\
\hline
\end{tabular}

Now, the distance of network source node from tank installation point, $L_{s}=50 \mathrm{~m}$. The optimal tank elevation is obtained as the least tank elevation using Eqn. 25, with a corresponding transmission line diameter for the optimal distribution network. $\mathrm{H}_{\mathrm{e}}$ is evaluated at each diameter (D) from the standard stock of Table 2. The least, but positive, $\mathrm{H}_{\mathrm{e}}$ value yields the optimal elevation. 
Hence, optimal tank elevation, $\mathrm{H}_{\mathrm{e}}=19.0936 \mathrm{~m}$ and corresponding transmission pipe size, $\mathrm{D}=0.0519938$ $\mathrm{m}$ (50mm (2") nominal pipe size, from Table 2).

\section{Conclusion}

A proposed water supply distribution network for a two-wing hostel with 10 blocks per wing and 20 rooms per block was analyzed by the Newton-Raphson Method. The need for compliance with velocity requirements of plumbing codes and the utilization of standard stock of industrially produced pipe sizes led to a pipe selectionadjustment algorithm for the sections of the network. The implementation of the algorithm generated the needed network parameters (e.g. Results Sets 1and 2) within a feasible computation time.

Tables 7(a) and 7(b) show the optimal ("best-of-the-rest") solution generated in yielding the least nodal head loss (pressure difference) relative to the source node (Node 1), which is the node having the highest pressure. It also reveals the pipe-set selection that goes along with the network. The corrected directions of flow in each pipe were also indicated. All flow types were found to be turbulent. Table 8 presents the nodal head loss relative to Node 1, and the absolute nodal (residual) pressures, when the first index node of the optimal solution set is set at the least pressure stipulated by the plumbing code (UPC). This mode of computation yields the optimal network in terms of pressure losses, in view of optimizing tank elevation.

Further results with the necessary transmission/main line size, and the optimal tank elevations at a distance of $50 \mathrm{~m}$ from the network source node (which are in line with the velocity requirements) were recorded by this analysis. It is recommended that analytical models dealing with distribution systems which incorporate minor losses should be the subject of further research.

\section{References}

1. Abdulhamid S. (2016). Design of Nonlinear Piping Water System Network by Using Newton Raphson Method. Journal of Mechanical and Civil Engineering (IOSR-JMCE), 13(2), 33-39

2. Cross, H. (1936). Analysis of Flow in Networks of Conduits or Conductors. Urbana University of Illinois, 286, 1-32

3. Engineering Encyclopedia, Absolute Pipe Roughness. (2011). Retrieved November 2nd, 2018, from EnggCyclopedia: https://www.enggcyclopedia.com/2011/09/absolute-roughess

4. Epp, R., \& Fowler, A. G. (1970). Efficient Code for Steady-State Flows in Networks. Journal of Hydraulics Division, ASCE, 96(HY1), 43-56.

5. Harrison, M. (2018). Schedule 40/80 PVC Pipe \& Fitting Specification. Retrieved November 2nd, 2018, from Harrison Machine \& Plastic Corporation: https:/www.harrisonplastic.com/pvcschedule40-80specs.html

6. Ideriah, F. J. (2017). Fundamentals of Fluid Mechanics (2nd Ed.). Port Harcourt: T \& D Press Limited.

7. Riley, K. F., Hobson, M. P. \& Bence, S. J. (2006). Mathematical Methods for Physics and Engineering $3^{\text {rd }}$ Ed., UK.: Cambridge University Press.

8. Kocyigit, M. B., Kocyigit, O, \& Safak, A. (2015). Abrasion Effect of Flow in Pipes. International Journal of Engineering \& Applied Sciences (IJEAS), 7(1), 9-24.

9. Nielsen, H. B. (1990). Methods for Analyzing Pipe Networks. ASCE Journals of Hydraulic Engineering, 115(2): 139-157

10. Swamee, P. K. \& Sharma, A. K. (2008). Design of Water Supply Pipe Networks. New Jersey. John Wiley and Sons, Inc.

11. Toldini, E., \& Pilati, S. (1988). A Gradient Algorithm for the Analysis of Pipe Networks. International Conference on Computer Applications for Water Supply and Distribution (System Analysis and Simulation), John Wiley and Sons, London, 1, 1-20.

12. Uniform Plumbing Code of Abu Dhabi (2016). An Environmental Guide for water supply and sanitation. Retrieved November 5th, 2018, from https://www.iapmo.org./docs/2016\%20UPC\%Report\%20on\%20Prposals.pdf

13. Wood, D. J. \& Charles, C. O. A. (1972). Hydraulic Network Analysis using Linear Theory. ASCE Journal of the Hydraulics Division, 98(HY7), 1157-1170. 